\title{
Analytcal Study of Gomti River Water
}

\author{
${ }^{1}$ Richa Khare and ${ }^{2}$ Smriti Khare \\ ${ }^{1,2}$ Amity School Of Engineering And Technology Amity University, U.P
}

\begin{abstract}
Water pollution is a major global problem. It is the leading worldwide cause of deaths and diseases which requires lot of changes and evaluation of water resource policy at all levels. Water pollution accounts for the deaths of more than 14,000 people daily. An estimated 700 million Indians have no access to a proper toilet, and 1,000 Indian children die of diarrheal sickness every day. All over the world we are seeing that drains are the main source of water pollution especially for rivers flowing within the city. These drains generally carry industrial effluent, domestic waste, sewage and medicinal waste resulting in poor water quality. Gomti river receives industrial as well as domestic wastes from various drains of Lucknow city. The extent to which these drains pollute the water quality of river Gomti in Lucknow city is not well documented yet. As Gomti river is the only source of surface water for the nearby communities. Due to increased pollution levels water quality of Gomti River is deteriorating continuously. Increased level of turbidity makes Gomti River water unpalatable, hence making it a matter of concern. The present study thus evaluates the effect of 26 drains on water quality of river Gomti in Lucknow city. The observed values of different physico-chemical parameters like pH, temperature, turbidity, total hardness(TH), Iron, total alkalinity (TA), Dissolved Oxygen (DO) of samples were compared with standard values recommended by World Health Organization (WHO). All the physico-chemical parameters for pre monsoon, monsoon and post monsoon seasons are within the highest desirable or maximum permissible limit set by $\mathrm{WHO}$ except turbidity which was high while $\mathrm{NO}_{3}{ }^{-}, \mathrm{Cl}$ and $\mathrm{F}$ are less than the values prescribed by WHO. The high level of pollutants disturbing the ecology of river and affecting human health directly and indirectly.
\end{abstract}

Key Words: Physico chemical parameters, $p H$ value, TSP, BOD, DO, TDS.

\section{Introduction}

Water pollution is a major global problem which requires ongoing evaluation and revision of water resource policy at all levels (international down to individual aquifers and wells). It has been suggested that it is the leading worldwide cause of deaths and diseases, and that it accounts for the deaths of more than 14,000 people daily. Gomti is at its worst at present. The summer months have never been good for the river's health. The flow of river gets reduced and so does the level of oxygen in it (1). It is under 'assault' at various points of its journey as it meanders through the 900-km stretch of rich alluvial plains of Uttar Pradesh. From industrial effluents to domestic discharge, the river becomes more of a flowing dumping yard for the 15 smaller and bigger towns, including Lakhimpur Kheri, Sitapur, Lucknow, Sultanpur and Jaunpur, in its catchment area (2). The river collects large amounts of human and industrial pollutants as it flows through the highly populous areas (18 million approx) of Uttar Pradesh. High pollution levels in the river have negative effects on the ecosystem of the Gomti, threatening its aquatic life. On 25 July 2008, foundation stone for a sewage treatment plant was laid, which would have a capacity of 345 million litre effluents per day (3). It is the domestic waste from all over the city that gets drained into Gomti via 26 waste water drains in Lucknow. The city consumes about 500 mld water everyday and produces $400 \mathrm{mld}$ as waste. Out of this, only $40 \mathrm{mld}$ gets treated at Gaughat while remaining 360 mld gets drained directly or indirectly into the river. ) Pollutants such as herbicides, pesticides, fertilizers and chemicals can make their way in to the river through drains of the whole city. This situation is really harmful for those areas where river water is the only source of drinking water; like Lucknow city .In present study we did analysis of different samples of water from different sites. 


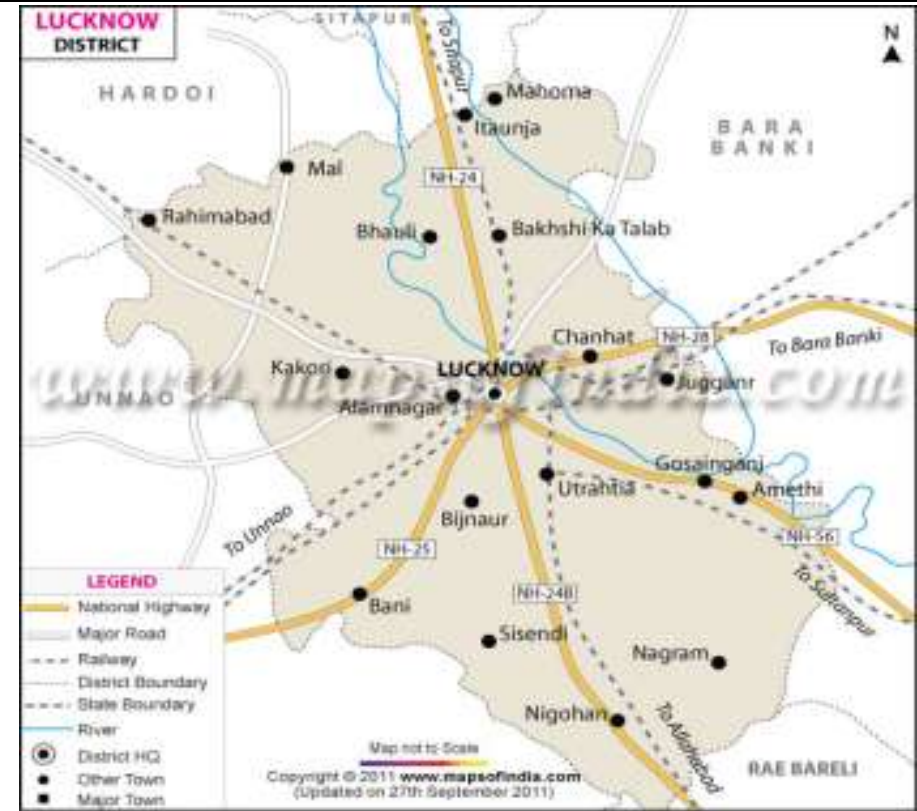

\section{Experimental}

Water sample collected from different sites of Lucknow.

Sample 1- Gomti river water from Kukral drainage.

Sample 2- Municipal water supply from town area Indiranagar .

Sample 3- Gaughat river water.

Sample 4- Aqua guard purified water which is collected from town area Lucknow city.

Sample 5- Industrial waste water near CDRI.

Sample 6- Talkatora which is near industrial area.

During sampling $\mathrm{pH}$ and temperature were determined using $\mathrm{pH}$ meter and thermometer respectively. The laboratory analysis of samples were done using standard methods. Titrimetric method was used for the determination of total alkalinity. Complexometric method was used for determining chloride content, whereas EDTA titrimetric method was used for total hardness analysis (4).

\section{Results}

Sample 1: Gomti river water from Kukral drainage

\begin{tabular}{|l|l|c|c|c|c|}
\hline No. & \multicolumn{1}{|c|}{ Parameters } & Units & \multicolumn{2}{|c|}{$\begin{array}{l}\text { Drinking Water } \\
\text { WHO Standard }\end{array}$} & $\begin{array}{l}\text { Experiment } \\
\text { Values }\end{array}$ \\
\hline & & & HDL & MPL & \\
\hline 1 & Colour & ---- & ---- & ---- & Colourless \\
\hline 2 & Odour & ---- & ---- & ----- & Odourless \\
\hline 3 & Temperature & ${ }^{0}$ C & $-\cdots--$ & $-\cdots--$ & 30 \\
\hline 4 & pH & ---- & $6.5-8.5$ & No relaxation & 7.7 \\
\hline 5 & Alkalinity & ppm & 200 & 500 & ---- \\
\hline 6 & Total Hardness & ppm & 300 & 580 & 736.84 \\
\hline 7 & $\begin{array}{l}\text { Chloride } \\
\text { Content }\end{array}$ & ppm & 250 & 1000 & 1065 \\
\hline 8 & $\begin{array}{l}\text { Dissolved } \\
\text { Oxygen }\end{array}$ & ppm & 2 & 6 & 1.2 \\
\hline
\end{tabular}

-The average values of physico-chemical parameters.

HDL: Highest Desirable Limit

MPL: Maximum Permissible Limit 
Analytcal Study of Gomti River Water

Sample 2 : Municipal water supply from town area Indiranagar

\begin{tabular}{|l|l|c|c|c|c|}
\hline No. & \multicolumn{1}{|c|}{ Parameters } & Units & \multicolumn{2}{|c|}{$\begin{array}{l}\text { Drinking Water } \\
\text { WHO Standard }\end{array}$} & $\begin{array}{l}\text { Experiment } \\
\text { Values }\end{array}$ \\
\hline & & & HDL & MPL & \\
\hline 1 & Colour & - & - & - & Colourless \\
\hline 2 & Odour & - & - & - & Odourless \\
\hline 3 & Temperature & ${ }^{0} \mathrm{C}$ & - & - & 30 \\
\hline 4 & pH & - & $6.5-8.5$ & No relaxation & 7.0 \\
\hline 5 & Alkalinity & ppm & 200 & 600 & - \\
\hline 6 & Total Hardness & ppm & 300 & 600 & 800 \\
\hline 7 & Chloride Content & ppm & 250 & 1000 & 200 \\
\hline 8 & Dissolved Oxygen & ppm & 2 & 6 & 3.7 \\
\hline
\end{tabular}

-The average values of physico-chemical parameters.

HDL: Highest Desirable Limit

MPL: Maximum Permissible Limit

Sample 3: Gaughat river water

\begin{tabular}{|l|l|c|c|c|c|}
\hline No. & \multicolumn{1}{|c|}{ Parameters } & Units & \multicolumn{2}{|c|}{$\begin{array}{l}\text { Drinking Water } \\
\text { WHO Standard }\end{array}$} & $\begin{array}{l}\text { Experiment } \\
\text { Values }\end{array}$ \\
\hline & & & HDL & MPL & \\
\hline 1 & Colour & - & - & - & Colourless \\
\hline 2 & Odour & - & - & - & Odourless \\
\hline 3 & Temperature & ${ }^{0} \mathrm{C}$ & - & - & 30 \\
\hline 4 & pH & - & $6.5-8.5$ & No relaxation & 7.2 \\
\hline 5 & Alkalinity & ppm & 200 & 600 & - \\
\hline 6 & Total Hardness & ppm & 300 & 600 & 510 \\
\hline 7 & Chloride Content & ppm & 250 & 1000 & 378 \\
\hline 8 & Dissolved Oxygen & ppm & 2 & 6 & 4.2 \\
\hline
\end{tabular}

-The average values of physico-chemical parameters.

HDL: Highest Desirable Limit

MPL: Maximum Permissible Limit

Sample 4

Aqua guard purified water which is collected from town area Lucknowcity

\begin{tabular}{|l|l|c|c|c|c|}
\hline No. & \multicolumn{1}{|c|}{ Parameters } & Units & \multicolumn{2}{|c|}{$\begin{array}{c}\text { Drinking Water } \\
\text { WHO Standard }\end{array}$} & $\begin{array}{l}\text { Experiment } \\
\text { Values }\end{array}$ \\
\hline & & & HDL & MPL & \\
\hline 1 & Colour & - & - & - & Colourless \\
\hline 2 & Odour & - & - & - & Odourless \\
\hline 3 & Temperature & 0 C & - & - & 30 \\
\hline 4 & $\mathrm{pH}$ & - & $6.5-8.5$ & No relaxation & 7.2 \\
\hline 5 & Alkalinity & ppm & 200 & 600 & - \\
\hline 6 & Total Hardness & ppm & 300 & 600 & 380 \\
\hline 7 & Chloride Content & ppm & 250 & 1000 & 905.25 \\
\hline 8 & Dissolved Oxygen & ppm & 2 & 6 & 3.6 \\
\hline
\end{tabular}

-The average values of physico-chemical parameters.

HDL: Highest Desirable Limit

MPL: Maximum Permissible Limit

Sample 5

Industrial waste water near CDRI

\begin{tabular}{|c|c|c|c|c|c|}
\hline No. & Parameters & Units & \multicolumn{2}{|c|}{$\begin{array}{l}\text { Drinking Water } \\
\text { WHO Standard }\end{array}$} & $\begin{array}{l}\text { Experiment } \\
\text { Values }\end{array}$ \\
\hline & & & HDL & MPL & \\
\hline 1 & Colour & ----- & ----- & ----- & Dirty Yellow \\
\hline 2 & Odour & ---- & ---- & ----- & Foul Smell \\
\hline 3 & Temperature & ${ }^{0} \mathrm{C}$ & ----- & ---- & 30 \\
\hline
\end{tabular}


Analytcal Study of Gomti River Water

\begin{tabular}{|l|l|c|c|c|c|}
\hline 4 & pH & ---- & $6.5-8.5$ & No relaxation & 7.5 \\
\hline 5 & Alkalinity & ppm & 200 & 600 & ---- \\
\hline 6 & Total Hardness & ppm & 300 & 600 & 836.84 \\
\hline 7 & Chloride Content & ppm & 250 & 1000 & 845.7 \\
\hline 8 & Dissolved Oxygen & ppm & 2 & 6 & 0.23 \\
\hline
\end{tabular}

-The average values of physico-chemical parameters.

HDL: Highest Desirable Limit

MPL: Maximum Permissible Limit

Sample 6

Talkatora Industrial area

\begin{tabular}{|c|c|c|c|c|c|}
\hline No. & Parameters & Units & \multicolumn{2}{|c|}{$\begin{array}{l}\text { Drinking Water } \\
\text { WHO Standard }\end{array}$} & $\begin{array}{l}\text { Experiment } \\
\text { Values }\end{array}$ \\
\hline & & & HDL & MPL & \\
\hline 1 & Colour & ----- & ----- & $\begin{array}{ll}---- \\
--\end{array}$ & Dirty Yellow \\
\hline 2 & Odour & ---- & ----- & ----- & Foul Smell \\
\hline 3 & Temperature & ${ }^{0} \mathrm{C}$ & ----. & ----- & 30 \\
\hline 4 & pH & ----- & $6.5-8.5$ & No relaxation & 8.2 \\
\hline 5 & Alkalinity & ppm & 200 & 600 & $\begin{array}{ll}---- \\
\end{array}$ \\
\hline 6 & Total Hardness & ppm & 300 & 600 & 860 \\
\hline 7 & Chloride Content & ppm & 250 & 1000 & $\begin{array}{ll}--- \\
-\end{array}$ \\
\hline 8 & Dissolved Oxygen & ppm & 2 & 6 & 0.6 \\
\hline
\end{tabular}

-The average values of physico-chemical parameters.

HDL: Highest Desirable Limit

MPL: Maximum Permissible Limit

\section{Conclusions}

Colour:- All the samples were colourless except industrial waste water which shows more contamination of these samples 5 and 6 .

Odour:- All the samples were colourless, except sample 5 and 6 which was found to be smelling foul. pH:- Sample 2 was having the minimum $\mathrm{pH}$ of 7.0 whereas sample 6 was having the maximum $\mathrm{pH}$ of 8.2. Alkalinity:- According to WHO standards HDL and MPL of for total alkalinity is 200-600 ppm. All samples show very high deviations from this value except sample 5 and 6 which contained only carbonate and bicarbonate ions. Hydroxyl ion $\left(\mathrm{OH}^{-}\right)$was absent in these two samples.

Total Hardness:- According to WHO standards, HDL and MPL of total hardness is 300-600 ppm. Sample 4 is the hardest of all.

Chloride content:- According to WHO standards, HDL and MPL of chloride is 250-1000 ppm. Sample 1 was having more value and sample 6 showed the result of chloride being absent in that.

Dissolved Oxygen:- According to WHO standards, HDL and MPL of dissolved oxygen is 2-6 ppm. All samples show deviation from this value which may be due to pollution at the sample sites.

The experiment shows that the information necessary for interpreting drinking water quality analysis. It focuses on testing results obtained from drinking water supplies of different areas of city. A large number of factors and geological conditions influence the correlations between different pairs of physico-chemical parameters of water samples.

\section{Discussion}

From the present study we conclude that Gomti water is most probably not fit for drinking and it requires lot of treatment to reduce the contaminations specially the alkalinity and hardness. To minimize the contamination of Gomti water at Lucknow city the values obtained had their significance level which help in selecting the proper methods for treatment of water because drinking water varies from place to place depending on the condition of the source from which it is drawn and the treatment done. The present study may prove to be useful to get pure water.

\section{References}

[1]. Gomti alarmingly polluted: IITR report Neha Shukla, TNN Jun 7, 2009, 03.50am IST

[2]. "Aiming for a scrubbed clean look". The Times Of India. 2010-01-28. Retrieved 2010-01-"Foundation laid for country's largest STP to clean Gomti in UP". 2008-07-25.

[3]. Engineering Chemistry, Shashi Chawla. 2011-2012. 